\section{The role of hydrogen sulfide in dentistry}

Dear Editor,

Till this date, hydrogen sulfide has shown applications in dentistry related to halitosis. This letter addresses recent updates about hydrogen sulfide in dentistry other than halitosis with emphasis on studies done in dental specialties, periodontology and orthodontics.

The hydrogen sulfide produced by Porphyromonas gingivalis enhances methyl mercaptan-induced pathogenicity in mouse abscess formation and plays a supportive role in inflammation caused by methionine $\gamma$-lyase. ${ }^{1}$ Exogenous hydrogen sulfide inhibits oral mucosal wound-induced macrophage activation via the nuclear factor- $\kappa \mathrm{B}$ pathway that may aid in controlling inflammation associated with mucosal wounds. ${ }^{2}$ Hydrogen sulfide induces the formation of nucleotide-binding domain and leucine-rich repeat containing protein 3 inflammasome-dependent interleukin $1 \beta$ and interleukin 18 secretion in human mononuclear leukocytes in vitro in the pathogenesis of periodontitis. ${ }^{3}$ Endogenous hydrogen sulfide is produced in human gingival tissue with expression of cystathionine $\beta$-synthase and cystathionine $\gamma$-lyase. ${ }^{4}$ Hydrogen sulfide promotes immunomodulation of gingiva-derived mesenchymal stem cells via the Fas/FasL coupling pathway. ${ }^{5}$

Hydrogen sulfide regulates bone remodeling and promotes orthodontic tooth movement by enhancing alveolar bone remodeling as a result of an increased osteoclastic activity and osteogenesis. ${ }^{6}$ Hydrogen sulfide may also be involved in the periodontal tissue remodeling during the orthodontic tooth movement as a result of accelerated periodontal ligament cell differentiation, tissue mineralization, bone formation and collagen synthesis. ${ }^{6}$ It can be inferred that more collaborative and extensive research in ultrastructural level should be done to uncover the therapeutic options of hydrogen sulfide in dentistry in future.

\section{Thorakkal Shamim*}

Department of Dentistry, Government Taluk Head Quarters Hospital, Malappuram, India

${ }^{*}$ Correspondence to: Thorakkal Shamim, shamu3duad@gmail.com. orcid: 0000-0002-6389-5417 (Thorakkal Shamim) doi: $10.4103 / 2045-9912.248272$

How to cite this article: Shamim T. The role of hydrogen sulfide in dentistry. Med Gas Res. 2018;8(4):185.

Copyright transfer agreement: The Copyright License Agreement has been signed by the author before publication.

Plagiarism check: Checked twice by iThenticate.

Peer review: Externally peer reviewed.

Open access statement: This is an open access journal, and articles are distributed under the terms of the Creative Commons AttributionNonCommercial-ShareAlike 4.0 License, which allows others to remix, tweak, and build upon the work non-commercially, as long as appropriate credit is given and the new creations are licensed under the identical terms.

\section{References}

1. Nakamura S, Shioya K, Hiraoka BY, et al. Porphyromonas gingivalis hydrogen sulfide enhances methyl mercaptan-induced pathogenicity in mouse abscess formation. Microbiology. 2018;164:529-539. .

2. Zhuang R, Guo L, Du J, Wang S, Li J, Liu Y. Exogenous hydrogen sulfide inhibits oral mucosal wound-induced macrophage activation via the NF-кB pathway. Oral Dis. 2018;24:793-801.

3. Basic A, Alizadehgharib S, Dahlén G, Dahlgren U. Hydrogen sulfide exposure induces NLRP3 inflammasome-dependent IL-1 $\beta$ and IL-18 secretion in human mononuclear leukocytes in vitro. Clin Exp Dent Res. 2017;3:115-120.

4. Chun-Mei J, Wu C, Guo-Liang M, Yue G, Ning C, Ji Y. Production of endogenous hydrogen sulfide in human gingival tissue. Arch Oral Biol. 2017;74:108-113.

5. Yang R, Yu T, Liu D, Shi S, Zhou Y. Hydrogen sulfide promotes immunomodulation of gingiva-derived mesenchymal stem cells via the Fas/ FasL coupling pathway. Stem Cell Res Ther. 2018;9:62.

6. $\mathrm{Pu} \mathrm{H}$, Hua Y. Hydrogen sulfide regulates bone remodeling and promotes orthodontic tooth movement. Mol Med Rep. 2017;16:9415-9422.

Received: 2018-10-02

Accepted: 2018-11-06 